\title{
SETTLEMENT PATTERNS, ANCIENT ROUTES AND ENVIRONMENTAL CHANGE IN SOUTH CAPPADOCIA (TURKEY), DURING THE HOLOCENE
}

\author{
Alvise MATESSI (ORCID: 0000-0003-0848-070X) ${ }^{1-3^{*}}$ \\ Emre DALKILIÇ (ORCID: 0000-0001-7136-8249) ${ }^{2}$ \\ Lorenzo D'ALFONSO(ORCID: 0000-0001-9163-3417) ${ }^{3, *}$
}

\author{
${ }^{1}$ University of Pavia, Department of Humanities, Italy \\ ${ }^{2}$ Middle East Technical University, Department of Archaeology, Ankara, Turkey \\ ${ }^{3}$ New York University, Institute for the Study of the Ancient World, NY, USA
}

Geliş / Received: 15.11.2018

Kabul / Accepted: 24.12.2018

\begin{abstract}
As a part of the Central Anatolian Plateau, South Cappadocia corresponds to today's province of Niğde. In this paper we will discuss the diachronic evolution of settlement pattern and the route network of this region, and their relation with major events of environmental and climatic change during the Holocene. We will argue that while human response to climate and environmental change is the reason for some major change in human geography, there are climate change events not reflected in settlement pattern and long-distance routes crossing the region, and major changes in human geography independent from environmental and climate change. A caseby-case analysis is therefore suggested as the correct approach to formulate a correct understanding of the human-landscape relation through time.
\end{abstract}

Keywords: south Cappadocia, settlement pattern, long distance routes, Holocene

\section{INTRODUCTION}

South Cappadocia (sC) covers an area roughly $20,000 \mathrm{~km} 2$. It consists of the wide Bor plain surrounded by by the Taurus Mountains (south), the Niğde Massif (north), and Hasan, Keçiboyduran and the Melendiz volcanoes (north). Finally, the northwestern part is defined by the Karacadağ. Surrounded by these mountains, the general geomorphology of the area can be identified as an area where a piedmont alluvial and colluvial fan encircles a core area of open steppe land corresponding to the floor of a Last Glacial Maximum lake dated around 26.5-17 ka ago. [1]

While the existence of a Pleistocene lake in the Bor plain has been long well-known, recent research by Gürel and Lermi[2], by Kuzucuoğlu and Gürel[1], and by Altin et al. [9] has shown that during the Holocene several episodes of shallow lake formation and paleosols formation also took place in the plain. These episodes have been interpreted as the consequence of climate change. Focusing on the Middle and Late Holocene, the $4.2 \mathrm{ka}$ $\mathrm{BP}$ event resulted in a drought that lasted through ca. 2300/2250 to $1950 \mathrm{BCE}$ and caused a reduction of the shallow lake levels in this area, and the formation of paleosols. Around 14th and 13th centuries BC, another climatic event, the $3.2 \mathrm{ka} \mathrm{BP}$ event, took place, which again resulted in a long-period drought in the Eastern Mediterranean. [1, 3,4]

\footnotetext{
* Corresponding author / Sorumlu yazar; e-mail: lda5@ nyu.edu
} 


\section{SETTLEMENT PATTERN AND ENVIRONMENTAL CHANGE}

A case study for the diachronic change of settlement pattern in the region has been produced by the 2006 2010 archaeological survey of the University of Pavia in SC. The survey covered an area of ca. $800 \mathrm{~km}^{2}$, defined by the southern slopes of the Hasan and Melendiz Mountains and the adjoining plain (Fig. 1). Since the survey covered different landscapes, the local developments are considered representative for the whole Bor basin. ${ }^{[1]}$

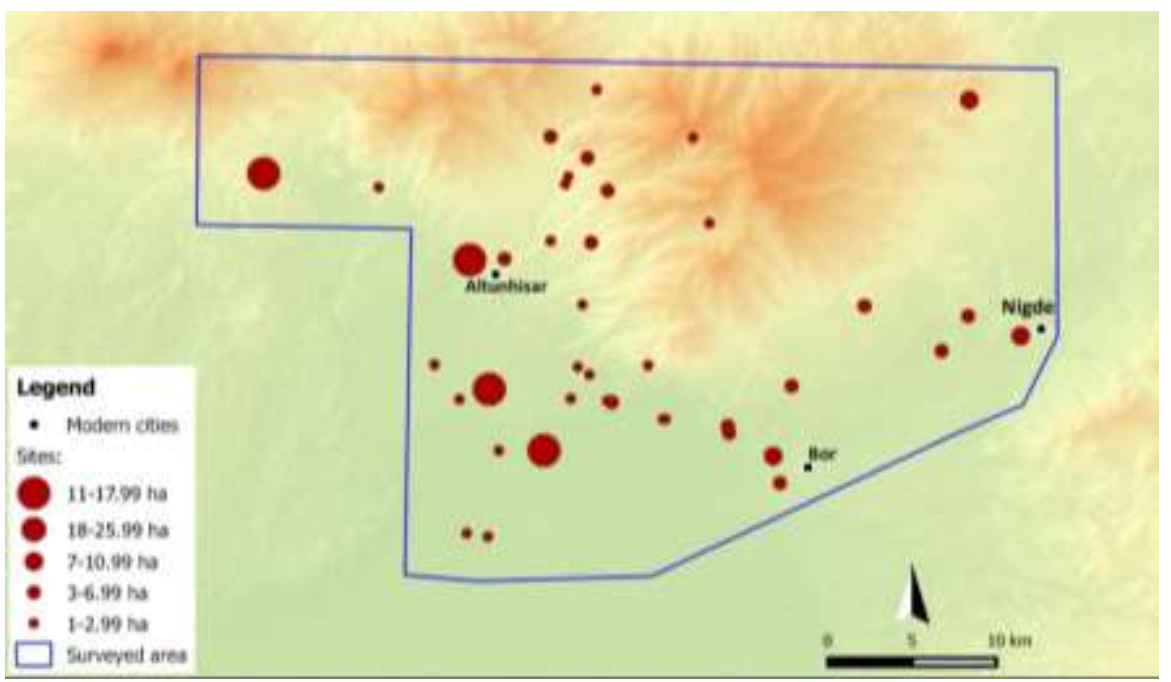

Fig. 1. Area of the archaeological survey of Pavia University. Dots represent the position of the sites, while the dimension of the dots is representative of the site surface (elaborated with QGIS by A. Matessi)

A total of 37 sites spanning more than 7000 years were visited, registered, and measured during the survey. They were geo-referenced by GPS, and their occupation was dated based on collection and study of the surface artifacts and their fragments, in particular ceramics.

The surface extension of the sites was used to identify different types of settlement.[12] 24 of the 37 sites were classified as very small, covering less than 2 ha: they are interpreted as hamlets, farms, and possibly strongholds (Medieval frouria). Nine represent ancient villages, with a surface area between $3-6$ ha. One is considered to be a small town, with an area of $7-10$ ha, while three of them have been major regional centers: one with a site size of ca. 24 ha, and the other two with a surface area bigger than 26 ha.[5]

The earliest occupation in the area dates between the Late Neolithic and the Chalcolithic period. This occupation is composed of small sites. Ceramic sherds belonging to these early periods have been also found on larger sites, but there is evidence that these multi-period sites, became large only in later periods. These sites were distributed along the mountain slopes but also well into the Bor plain (Fig. 2A).

The Early Bronze Age (EBA) I-II, corresponding to ca. 3000-2300 BCE [13], shows a substantial continuity in site dimension and area of distribution of the settlements with the previous period. In fact, the first discontinuity is visible after the EBA II. EBA III and Middle Bronze Age sites are no longer located midst the Bor Plain, but only on its northern ridge (Fig. 2B). This was likely connected with the $4.2 \mathrm{~K}$ BP drought event, causing the retraction of the shallow lakeshore on which villages in earlier time were built. The population moved to the mountain slopes, likely in the vicinity of karstic springs or mountain streams. If climatic change is a likely factor in explaining the move of the sites towards the piedmont area, new ongoing socio-economic and technological developments taking place in central and western Anatolia[13] are however responsible for the shift in site dimension from a hamlets-\&-villages landscape to a fortified-town landscape. One of them, Kınık Höyük, with an overall surface of $24 \mathrm{ha}$, is the main pre-classical site of $\mathrm{sC}$, together with Kemerhısar/ Tuwanuwa. Despite their dimension, the reduction of the number of site to two is indicative of a demographic slump.

During the Late Bronze Age (LBA), the change in the settlement pattern started in the EBA III becomes complete (Fig. 2C). The four LBA sites are located along the southern foothills of the Melendiz Mountain at regular distance of ca. $10 \mathrm{~km}$ from one another. At the end of the LBA and the beginning of the Iron Age (IA), the aforementioned $3.2 \mathrm{ka} \mathrm{BP}$ climatic event took place, accompanied by crises and abrupt change in settlement pattern and material culture in Anatolia as well as in the Eastern Mediterranean in general.[3,4] Interestingly, sC is an exception to this trend, and IA settlement pattern continues the one of the LBA. Material culture shows 


\section{SETTLEMENT PATTERNS, ANCIENT ROUTES AND ENVIRONMENTAL CHANGE IN SOUTH CAPPADOCIA (TR), DURING THE HOLOCENE}

some evidence of evolution, but technology of ceramic production and organization of staple storage, only to mention two main features, remain the same.[6,7] This continuity is peculiar to this region, and it is likely linked with the richness of water of the piedmont colluvial fans all around the Bor-Eregli Plain. As in the LBA, IA town-large sized sites in the surveyed area are set at regular distance along the slopes of the Melendiz Mountain (Fig. 2D).

Settling of the mountain area starts during the Hellenistic and Roman period (Fig. 2E). On the plain, the site number also grows, and smaller sites hierarchically dependent on town-sized sites are registered. In this case change in technology and territorial organization due to the direct intervention of the Roman, population growth and the implantation of Roman colonists are the most likely reasons for the change in settlement pattern.

The most significant change together with the one occurring at the end of EBA II happened during the early Medieval period, when the size of settlements starts to vary immensely from small fortresses and hamlets to big cities (Fig. 2F). In this case, again, the impact of the Arab raids was responsible for the move of part of the population from the plain to the mountains, where also large cities formed in protected areas, as for Avören, or underground area, as for the Altunhisar underground city.[5]

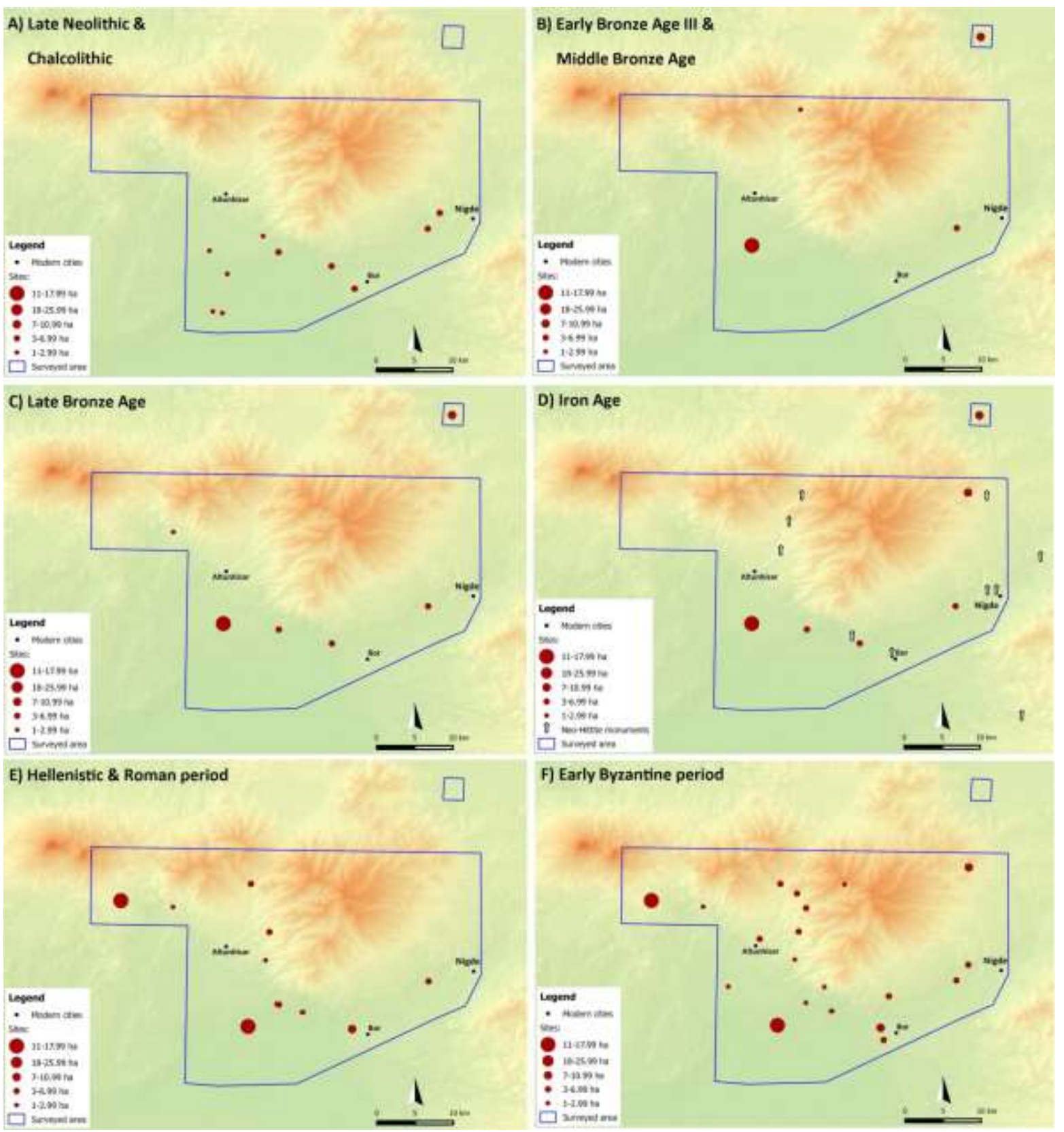

Fig. 2. Evolution of the settlement pattern in the area surveyed by Pavia University 2006-2009 during the Holocene (elaborated with QGIS by A. Matessi) 


\section{DIACHRONIC CHANGE OF PATHWAYS WITHIN SOUTH CAPPADOCIA}

In the absence of geomorphological remains visible on the terrain or by aerial/satellite imagery, three elements need to be taken into account to reconstruct ancient routes: the distribution of sites and landmarks identifying routes; the identification of the least cost pathway, assuming that this would be convenient for populations in the past; the historical accounts about ancient roads. Written sources exist for sC only from ca. $1500 \mathrm{BCE}$.
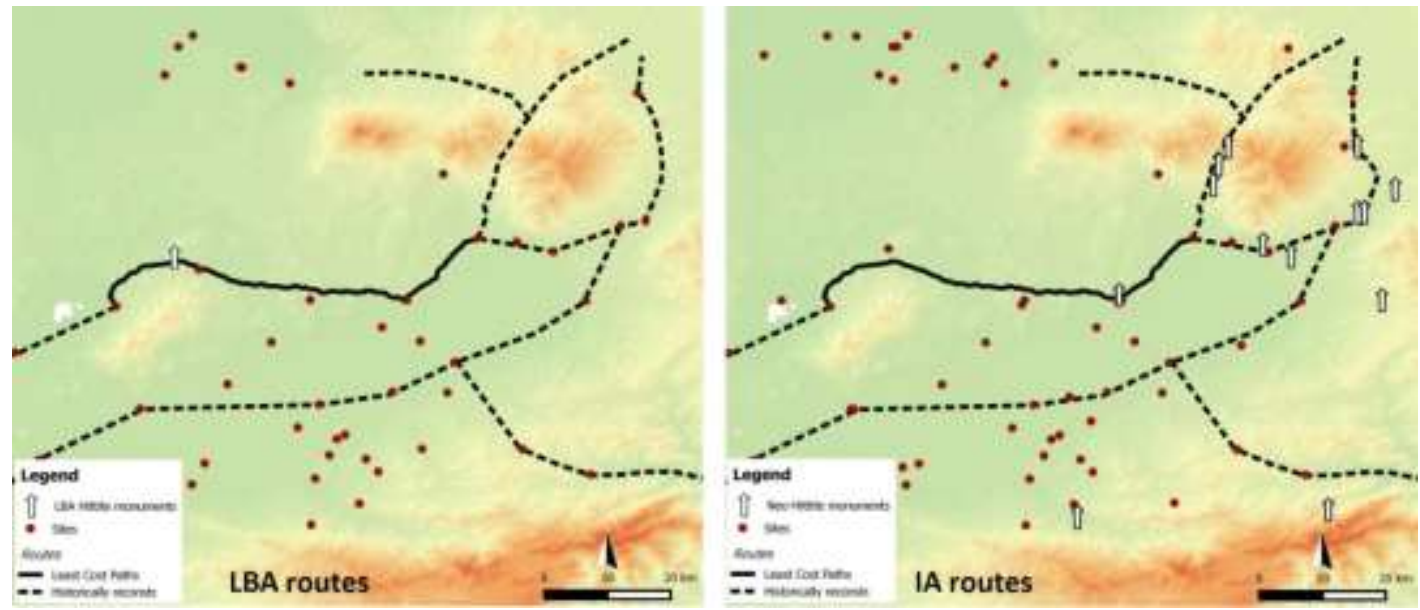

Fig. 4. The road system in preclassical sC (LBA \& IA), and the data about continuity vs abandonment of sites comparing south Cappadoca with the Knoya plain, to the west.

Starting from that time, until the 16th century AD, sC was a major crossroad between Europe, Central Anatolia and the Levant. More specifically, sC controlled the route towards the Göksu Valley, and the one towards today's Pozantı, These were the two passages through the Taurus connecting south-central Anatolia and Cilicia.[5] While much attention has been devoted in research to the pathway connecting Cilicia with the Plateau, the ancient road network organized north of the Taurus was barely the focus of scholarly discussion until recently. For the period $1500 \mathrm{BCE}-500 \mathrm{AD}$ there is enough archaeological and textual evidence to study the road systems and its change across time.

Comparing settlement data from Southern Cappadocia with those from the Konya plain, Matessi et al.[1] could show that only minor changes affected the settlement pattern as well as the route system of SC in the passage from the LBA (collapse of the Hittite Empire) to the IA (Fig. 4). Considered the climatic and political change characterizing the end of the 2nd millennium BCE in the eastern Mediterranean, this is one more evidence of the peculiar trajectory of $\mathrm{sC}$ in this period. For the Hellenistic and Roman periods, Turchetto suggests that the road system was similar to that of the previous periods.[12]

Comparing this ancient route system with today's ones, no routes were crossing the center of the Bor plain in the past. Passing from marsh and shallow lakes in wet periods, to arid/steppe in dry periods, in no way was this a sustainable landscape for settling, or for crossing the region.

A second major difference emerges from the analysis of the itineraries in the north-western portion of the region, connecting Aksaray to Ulukışla. Today's road runs along the eastern shore of Tuz Gölü, then along the western slopes of the Hasan Dağ finally skirting the southern slopes of the Cappadocian volcanos along the Altunhısar-Bor Yolu and bending south towards Kemerhisar. The Roman itinerary between Garsauria-Aksaray and Tyana-Kemerhısar, preserved on the Tabula Peutingeriana (2nd c. CE), run along the very same pathway. [12]

The analysis of written sources and settlement pattern in pre-classical times strongly suggests that this itinerary was not in use before the Roman period. No major site dating between $2000 \mathrm{BCE}-500 \mathrm{BCE}$ arose along the western and south-western slopes of the Hasan Dağı. On the opposite, a pathway covering the northern slopes of the Hasan Dağı into the Melendiz valley and then crossing the volcanic region along the Ihlara - Ulukışla pass and along the Altunhisar valley is supported by textual and archaeological evidence. [1] The ancient road skirting the eastern slope of the Hasan Dağı connected two large centers occupied from the late Hellensitic to the Medieval periods, namely Viranşehir on the northern slopes of the Hasan Dağı, overlooking the Melendiz Plain, and Avören, on the southeastern slopes of the Hasan Dağı, overlooking the Bor Plain (Fig. 5).[1] 


\section{SETTLEMENT PATTERNS, ANCIENT ROUTES AND ENVIRONMENTAL CHANGE IN SOUTH CAPPADOCIA (TR), DURING THE HOLOCENE}

The pathway through the Altunhisar valley is even better documented. The presence of an EBA site at Tavşantepe is indicative of a pathway towards the valley already at the end of the 3rd millennium BCE. During the IA, four stele set at almost regular distance along the Altunhisar valley signaled a route departing from the site of Kınık Höyük (ancient Tupaziya/ Tracias/ Drizion) towards the pass of Tavşantepe (Figs. 4-5). During the early Christian period, a church (Okçuören/Kilise-öreni), close to the pass, served as a post for pilgrims along their way towards the Holy Land. Although the itineraries from Aksaray through the Melendiz valley and through the high mountains of the region would have been harder than the ones along the plain due to the elevation and the length of the pathway, they passed through a landscape rich in water (springs and torrents), but also in game.

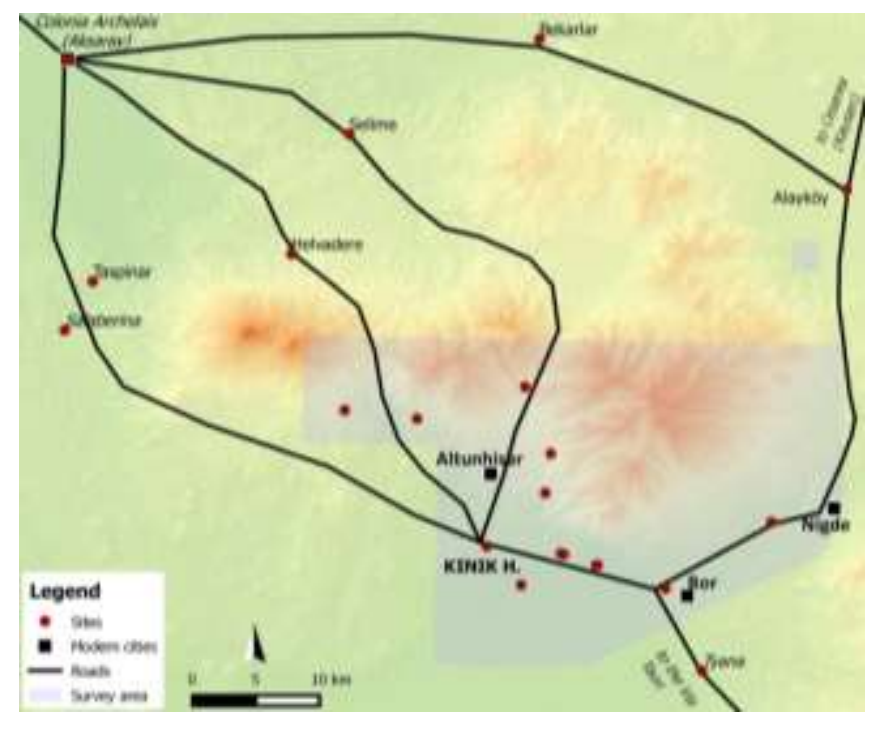

Fig. 5. Ancient routes from Aksaray to Tyana, Kemerhısar

\section{CONCLUSIONS}

Climatic change and change in road system and settlement pattern may be related with each other, but this is not necessarily given. Change in settlement pattern in $\mathrm{sC}$ is in one case (4.2 ka BP) linked with climate change, but in other cases it depends on wars, new socio-economic conditions, and new technologies. On the other hand, during the much troubled LBA-IA transition, characterized by climate change and socio-political upheaval, settlement pattern and route system of $\mathrm{sC}$ did not change. The analysis of the route system shows a great continuity throughout $1500 \mathrm{BCE}-500 \mathrm{CE}$. However the existence of main routes across the volcanic mountains towards the south in order to reach the Bor plain and continue towards Cilicia implies the preference for secure, water rich areas vs lower costs pathways, particularly in pre-Roman times. As a general observation, we may conclude that a more conservative approach to the location of settlement and roads, close to water springs may be considered one of the reasons that allowed the ancient local population to experience a great cultural and socio-political continuity in times of profound distress. One might suggest that the territorial organization set up in response to crisis due to climate change and political instability at the end of the $3^{\text {rd }}$ millennium was maintained and implemented along the $2^{\text {nd }}$ millennium in this region in a way that allowed the local population to better respond and face the new crisis of the end of the millennium.

\section{REFERENCES}

[1] MATESSi A., GÜREL A., KUZUCUOĞLU C., and D’ALFONSO L., East of Konya: Settlements, Routes and Environment in Southern Cappadocia, and the Political Landscape of South Central Anatolia during the Second Millennium BCE. Crossroads: The Konya Plain from Prehistory to the Byzantine Period. Ege Yayınları, Istanbul, 2018.

[2] GÜREL A., LERMI, A., Pleistocene-Holocene Fills of the Bor-Ereğli Plain (Central Anatolia). GeoArchaeological Activities in Southern Cappadocia, Turkey. Italian University Press, Pavia, Italy, 2010. 
[3] KUZUCUOĞLU, C., The rise and fall of the Hittite State in central Anatolia: how, when, where, did climate intervene?. La Cappadoce meridional de la préhistoire à la period byzantine, Ege Yayınları, Istanbul, 2015.

[4] KANIESWKi D., VAN CAMPO E., GUIOT J., LE BUREL S., OTTO, T. BAETEMAN C., Environmental Roots of the Late Bronze Age Crisis. PLoS ONE 8(8), 2013.

[5] D'ALFONSO L., Geo-Archaeological Survey in Northern Tyanitis and the Ancient History of Southern Cappadocia. Geo-Archaeological Activities in Southern Cappadocia, Turkey, Italian University Press, Pavia, Italy, 2010.

[6] MORA, C., D'ALFONSO, L., Anatolia after the End of the Hittite Empire. New Evidence from Southern Cappadocia. Origini 34, 2012.

[7] CASTEllanO, L., Staple Economies and Storage in Post-Hittite Anatolia. Journal of Eastern Mediterranean Archaeology and Heritage Studies, 2018.

[8] BERGES D., NOLLÉ, J., Tyana. Habelt, Bonn, Germany, 2000.

[9] ALTIN T.B., EL OUAHABI M., FAGEL, N., Environmental and Climatic Changes during the Pleistocene-Holocene in the Bor Plain, Central Anatolia, Turkey. Palaeogeography, Palaeoclimatology, Palaeoecology 440, 2015.

[10] ÖKSE, T., Hethiterforschung anhand von Geländebegehungen. Strukturierung und Datierung in der hethitischen Archäologie, BYZAS 4, Ege Yayınları, Istanbul, Turkey, 2006.

[11] DÜRING B., The Prehistory of Asia Minor: From Complex Hunter-Gatherers to Early Urban Societies. Cambridge University Press, Cambridge, United Kingdom, 2011.

[12] TURCHETTO, J., Per Cappadociae partem...iter feci. Graeco-Roman Routes between Taurus and Halys. Fabrizio Serra Editore, Pisa - Roma, Italy, 2018. 